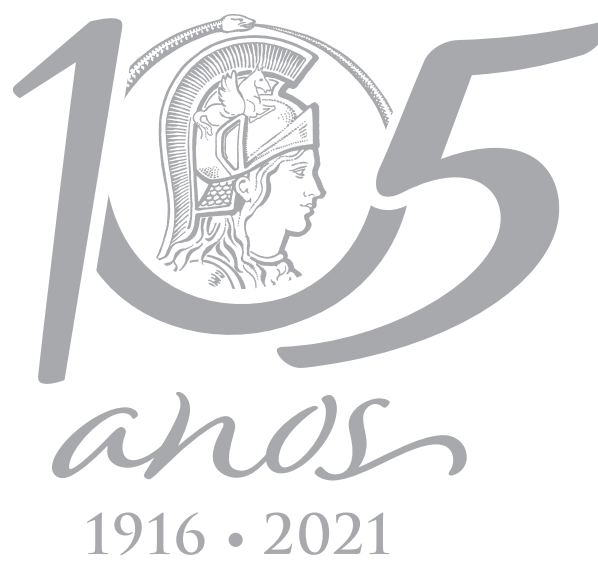

An Acad Bras Cienc (2021) 93(4): e20200774 DOI 10.1590/0001-3765202120200774

Anais da Academia Brasileira de Ciências | Annals of the Brazilian Academy of Sciences Printed ISSN 0001-3765 I Online ISSN 1678-2690

www.scielo.br/aabc | www.fb.com/aabcjournal

PHYSICAL SCIENCES

\title{
Hierarchical Structure and Magnetic Behavior of Zn-Doped Magnetite Aqueous Ferrofluids Prepared from Natural Sand for Antibacterial Agents
}

\author{
AHMAD TAUFIQ, DEFI YULIANTIKA, SUNARYONO SUNARYONO, ROSY E. SAPUTRO, \\ NURUL HIDAYAT, NANDANG MUFTI, HENDRA SUSANTO, SIRIWAT SOONTARANON \\ \& HADI NUR
}

\begin{abstract}
This study performs natural sand-based synthesis using the sonochemical route for preparing $\mathrm{Zn}$-doped magnetite nanoparticles. The nanoparticles were dispersed in water as a carrier liquid to form $\mathrm{Zn}$-doped magnetite aqueous ferrofluids. Structural data analysis indicated that the $\mathrm{Zn}$-doped magnetite nanoparticles formed a nanosized spinel structure. With an increase in the $\mathrm{Zn}$ content, the lattice parameters of the $\mathrm{Zn}$-doped magnetite nanoparticles tended to increase because $\mathrm{Zn}^{2+}$ has a larger ionic radius than those of $\mathrm{Fe}^{3+}$ and $\mathrm{Fe}^{2+}$. The existence of $\mathrm{Zn}-\mathrm{O}$ and $\mathrm{Fe}-\mathrm{O}$ functional groups in tetrahedral and octahedral sites were observed in the wavenumber range of 400-700 $\mathrm{cm}^{-1}$. The primary particles of the $\mathrm{Zn}$-doped magnetite ferrofluids tended to construct chain-like structures with fractal dimensions of 1.2-1.9. The gas-like compression (GMC) plays as a better model than the Langevin theory to fit the saturation magnetization of the ferrofluids. The ferrofluids exhibited a superparamagnetic character, with their magnetization was contributed by aggregation. The $\mathrm{Zn}$-doped magnetite ferrofluids exhibited excellent antibacterial activity against gram-positive and negative bacteria. It is suggested that the presence of the negatively charged surface and the nanoparticle size may contribute to the high antibacterial activity of Zn-doped magnetite ferrofluids and making them potentially suitable for advanced biomedical.
\end{abstract}

Key words: Iron sand, Zn-doped magnetite, aqueous ferrofluid, fractal structure, antibacterial agent.

\section{INTRODUCTION}

Nanomaterials in the range 1-100 $\mathrm{nm}$ have become essential owing to their increased surface-to-volume ratio. Magnetite, as a nanomaterial, has broad advanced applications in various fields, particularly in medical and biological areas. During the last five years, it has been reported that magnetite nanoparticles have potential applications in cancer therapy (Farzin et al. 2019), as organic-inorganic Bronsted acid catalyst (Maleki et al. 2019), as contrast agents for computed tomography scanning and magnetic resonance imaging (Sood et al. 2017), in bioseparation (Adams et al. 2018), in thermal treatment and bioimaging (Yang et al. 2017), as carriers for removal $\mathrm{Cr}(\mathrm{VI})$ from 
aqueous solution (Zhou et al. 2020), in targeted anticancer drug delivery system (Yew et al. 2020), and as an antibacterial agent (Jency et al. 2020).

The integration of medicine and nanotechnology offers new prospects for treating human diseases (Yan et al. 2019). Recently, the antibacterial performance of nanomaterials has received global attention owing to its significant advantages in inhibiting bacterial growth rates, and these have been propounded as nanomedicines. Nanoparticle activities in biological processes have been scrutinized because of the extensive development of biotechnology combined with nanotechnology in biomedical sciences. Their significant toxicity to bacteria suggests that nanoparticles could play a fundamental role as future bactericides. The high biocompatibility of nanoparticles makes them potentially promising as safety agents in living organisms. Although their medical application using antibiotics is well established, there is limited information on how liquid nanoparticles, especially in ferrofluids, can be postulated as secondary bactericides in medical treatment. Therefore, to allow their more specific application as powerful antibacterial agents, it is essential to produce magnetite nanoparticles in magnetite ferrofluids.

Practically, magnetite ferrofluids can be produced by coating magnetite nanoparticles and dispersing them in an appropriate carrier liquid. A coating agent using a surfactant and carrier liquid plays a vital role in providing highly stable ferrofluids for antibacterial agents (Petrenko et al. 2018). Therefore, herein, we focused on using water as a carrier liquid to produce the aqueous magnetite ferrofluids owing to their simplicity, stability, and biocompatibility. Nevertheless, despite producing magnetite nanoparticles in aqueous ferrofluids, combining magnetite nanoparticles with metals and metal oxides has also become an essential method for enhancing their antibacterial performance, such as in magnetite/mordenite/CuO core-shell nanocomposites (Rajabi \& Sohrabnezhad 2018), magnetite/Ag nanocomposites (Amarjargal et al. 2013) $\left(\mathrm{SiO}_{2} / \mathrm{SnO}_{2}\right) @ \mathrm{ZnO} @ \mathrm{Fe}_{3} \mathrm{O}_{4}$ nanocomposites (Sekhar et al. 2019), $\mathrm{Fe}_{3} \mathrm{O}_{4} @ \mathrm{PEG}-\mathrm{SO}_{3} \mathrm{H}$ nanocomposite (Maleki et al. 2018), magnetite- $\mathrm{TiO}_{2}$ nanosheets (Ma et al. 2015), magnetite/ $\mathrm{TiO}_{2}$ core/shell nanoparticles (Chen et al. 2008), and hyperbranched magnetite/polyurethane nanocomposites (Das et al. 2013). Introducing an appropriate transition metal into magnetite is also one of the most potent methods for increasing the antibacterial activity. A recent study shows that the $\mathrm{Zn}$-doped magnetite exhibits a superior antibacterial performance than a pure magnetite nanoparticle (Anjana et al. 2018). However, this work used only one Zn composition, and was not yet fabricated as ferrofluids form. It is noteworthy that the $\mathrm{Zn}$ content may further affect the particle size and structural, and magnetic properties of the $\mathrm{Zn}$-doped magnetite ferrofluids, resulting in changes in their antibacterial performance. Therefore, a comprehensive study involving the variation of the $\mathrm{Zn}$ composition is required to obtain an appropriate composition for optimizing the antibacterial performance of $Z n$-doped magnetite. Moreover, to reduce the mass production cost, it is essential to produce high-quality Zn-doped magnetite ferrofluids using an inexpensive main precursor and simple technique. Interestingly, natural sand, which is inexhaustible around the world and especially in all areas of Indonesia, offers new possibilities for generating Zn-doped magnetite ferrofluids.

In the application step, the critical process is the synthesis of the ferrofluids, which determines the physicochemical properties and thermodynamic activities within the living materials (Taufiq et al. 2018). Interestingly, the sonochemical technique allows the production of high-purity magnetic nanoparticles with uniform size and high top surface area to bind with living material on cell 
membranes and walls. This characteristic showed a linear relation with solubility in an aqueous environment as in fluids in living organisms. It plausibly causes the nanoparticles' biological features to generate different activities among those nanoparticles. Furthermore, this study employed a sonochemical technique primarily owing to its advantages in generating negative pressure against intermolecular binding in fluidic media, easily forming smaller particles and effectively preventing agglomeration (Sancheti \& Gogate 2017). Therefore, herein, we report the synthesis of Zn-doped magnetite ferrofluids from natural sand by employing the sonochemical technique. Furthermore, selected properties, such as hierarchical structure, particle size and morphology, functional group, magnetization, and antibacterial activity, based on a dilution method, are also discussed.

\section{MATERIALS AND METHODS}

Natural sand was utilized as the primary precursor in synthesizing the Zn-doped magnetite nanoparticles using the sonochemical route. The natural sand was obtained from Sine Beach located in Tulungagung Regency, East Java, Indonesia (geographic coordinates of $8^{\circ} 17^{\prime} 28.3^{\prime \prime} \mathrm{S} 111^{\circ} 56^{\prime} 06.7^{\prime \prime} \mathrm{E}$ ). First, magnetite $\left(\mathrm{Fe}_{3} \mathrm{O}_{4}\right)$ powder extracted from natural sand was made to react with hydrochloric acid (Sigma Aldrich, PA) at room temperature to obtain $\mathrm{FeCl}_{3}$ and $\mathrm{FeCl}_{2}$ solutions, as shown in Equation 1. This reaction was maintained by employing a magnetic stirrer for 20 min at ambient temperature.

$$
\begin{gathered}
\mathrm{Fe}_{3} \mathrm{O}_{4}+8 \mathrm{HCl} \longrightarrow \mathrm{FeCl}_{2}+2 \mathrm{FeCl}_{3}+\mathrm{H}_{2} \mathrm{O} \\
(1-y) \mathrm{FeCl}_{2}+2 \mathrm{FeCl}_{3}+y \mathrm{ZnCl}_{2}+8 \mathrm{NH}_{4} \mathrm{OH} \longrightarrow \mathrm{Zn}_{y} \mathrm{Fe}_{3}-y \mathrm{O}_{4}+4(1+\mathrm{y}) \mathrm{H}_{2} \mathrm{O}+8 \mathrm{NH}_{4} \mathrm{Cl}
\end{gathered}
$$

The resultant product shown in Equation 1 was then made to react with $\mathrm{ZnCl}_{2}$ (Sigma Aldrich, PA) based on the targeted $\mathrm{Zn} /$ Fe ratio and titrated with ammonium hydroxide (Sigma Aldrich, PA) using an ultrasonic bath with a frequency of $40 \mathrm{kHz}$ to yield a black precipitate. This reaction was predicted using Equation 2. The $y /(y-3)$ compositions ( $\mathrm{Zn} /$ Fe ratios) of the samples were 0, 0.03, 0.07, 0.10, and 0.13 . These samples were coded as $Y_{1}, Y_{2}, Y_{3}, Y_{4}$, and $Y_{5}$, respectively. Samples were washed with distilled water several times until a normal $\mathrm{pH}$ was achieved to remove the remaining products shown in Equation 2. Herein, the $\mathrm{Zn}$-doped magnetite powders were prepared by drying the final products at $100^{\circ} \mathrm{C}$ for one hour. Meanwhile, the $\mathrm{Zn}$-doped magnetite ferrofluids were prepared by coating the Zn-doped magnetite powders using tetramethylammonium hydroxide (Sigma Aldrich, PA) and then dispersed in water.

The prepared samples were characterized by the X-ray diffraction (XRD) technique using an X-ray diffractometer (X'Pert Pro, PanAnalytical, Netherlands) with CU-K $\alpha$ radiation (1.5406 $\AA$ ) and 2-theta in the range of $20^{\circ}-80^{\circ}$, a transmission electron microscopy (TEM, JEOL JEM 1400, Japan) at a magnification of 150,000×, a Fourier transform infrared (FTIR) spectroscopy (IRPrestige-21 spectrophotometer, Shimadzu, Japan) in the wavenumber range of $400-4000 \mathrm{~cm}^{-1}$, a vibrating sample magnetometer (VSM) using OXFORD $1.2 \mathrm{H}$ machine (Oxford Instrument, UK) with an applied magnetic field in the range of $-1 \mathrm{~T}$ and $1 \mathrm{~T}$, and synchrotron-based small-angle X-ray scattering (SAXS) BL 1.3 SAXS owned by Synchrotron Light Research Institute-Thailand to investigate the structure, particle size and morphology, functional group, and magnetic properties. In this study, all characterizations were maintained at ambient temperature. Meanwhile, the antibacterial performances of the Zn-doped magnetite ferrofluids were investigated using a colony test employing E. coli and B. subtilis bacteria. 
All the characterization processes were conducted at ambient temperature. Approximately $0.1 \mathrm{mg}$ of E. coli and B. subtilis bacteria were suspended in $1 \mathrm{ml}$ liquid nutrient. The sample was then incubated at room temperature for $24 \mathrm{~h}$. The bacterial suspension was diluted with liquid nutrients, resulting in a similar density to that of the McFarland standard. The following step involved subculture on Mueller-Hinton agar (MHA) medium and incubation for $24 \mathrm{~h}$. The colony count method was used to determine the bacterial growth rate in the medium and the number of bacterial colonies in this control group. As a negative control group, other samples were treated with $0.1 \mathrm{~g}$ erythromycin antibiotic dissolved in $1 \mathrm{ml}$ of liquid nutrient. In the next step, a $0.5 \mathrm{ml}$ antibiotic solution was mixed with $4.5 \mathrm{ml}$ bacterial suspension. The sample was incubated at room temperature for $24 \mathrm{~h}$ and subcultured on the MHA medium. The last stage involved measuring the growing colonies on the media through colony quantification. However, the treatment group was prepared by diluting $0.5 \mathrm{ml}$ ferrofluids with $4.5 \mathrm{ml}$ bacterial suspension to obtain a total bacterial concentration of $5 \times 10^{5} \mathrm{CFU} / \mathrm{ml}$. These samples were then incubated for $24 \mathrm{~h}$ and subcultured on the MHA medium to observe the colony formation. As in the previous steps, the total number of colonies formed was measured using a colony count method.

\section{RESULTS AND DISCUSSION}

The XRD patterns of the prepared Zn-doped magnetite powders, as shown in Figure 1a, are represented by circles, whereas the quantitative data analysis results (fitting model) performed using the Rietveld method by employing the Rietica program are represented by solid black lines. Visually, the solid black lines coincide with the circles, indicating that the crystal structure model using ICSD 30860 for magnetite agrees well with the experimental data. The XRD results showed that all dominant diffraction peaks were detected as the magnetite phase with hkl planes of (220), (311), (400), (422), (511), (440), and (533) denoted by XRD peaks at 30.31 ${ }^{\circ}, 35.68^{\circ}, 43.40^{\circ}, 53.84^{\circ}, 57.44^{\circ}, 62.96^{\circ}$, and $74.22^{\circ}$ respectively. Samples $Y_{1}, Y_{2}, Y_{3}, Y_{4}$, and $Y_{5}$ have $\mathrm{Zn} /$ Fe ratios of $0,0.03,0.07,0.10$, and 0.13 , respectively. Based on the qualitative data analysis for Figure 1a, all samples exhibited similarly XRD patterns, showing no impurity phases.

The quantitative data analysis for Figure $1 \mathrm{~b}$ presented that each sample had a different peak position for the highest peak. The increasing Zn content generally tended to change the 2-theta to a lower value, indicating the decreasing particle size of the samples due to the formation of crystal defect (Kucuk 2019).The crystal defect could be observed by the shiftiness of diffraction peak at 2-theta (311), indicating that the $\mathrm{Zn}^{2+}$ ions had successfully replaced $\mathrm{Fe}^{2+}$ and $\mathrm{Fe}^{3+}$ in the spinel system. According to the Bragg law, the displacement of the diffraction peak to a lower position of 2-theta increases the lattice parameters. The data analysis results such as 2-theta position for the highest peak, lattice parameters, crystal volume, molecular weight, crystallite size, and ionic distribution of the samples are listed in Table I. All samples had a spinel cubic structure constructed by two sublattices, i.e., tetrahedral (A) and octahedral (B) sites. All samples formed a crystal structure with a space group $\mathrm{Fd}-3 \mathrm{~m}$ Z. The ionic distribution of the Zn-doped magnetite was calculated based on the previous works (Liu et al. 2016, Modaresi et al. 2019, Behdadfar et al. 2012, Lv et al. 2015, Simmons et al. 2015). Based on Table I, it can be inferred that increasing the $\mathrm{Zn}$ content tends to increase the lattice parameters $(a=b=c)$ of the samples. Theoretically, this increase resulted from an increase in the content of $\mathrm{Zn}^{2+}$, which has a larger ionic radius than that of $\mathrm{Fe}^{2+}$ and $\mathrm{Fe}^{3+}$ (Mozaffari et al. 2015). Furthermore, 

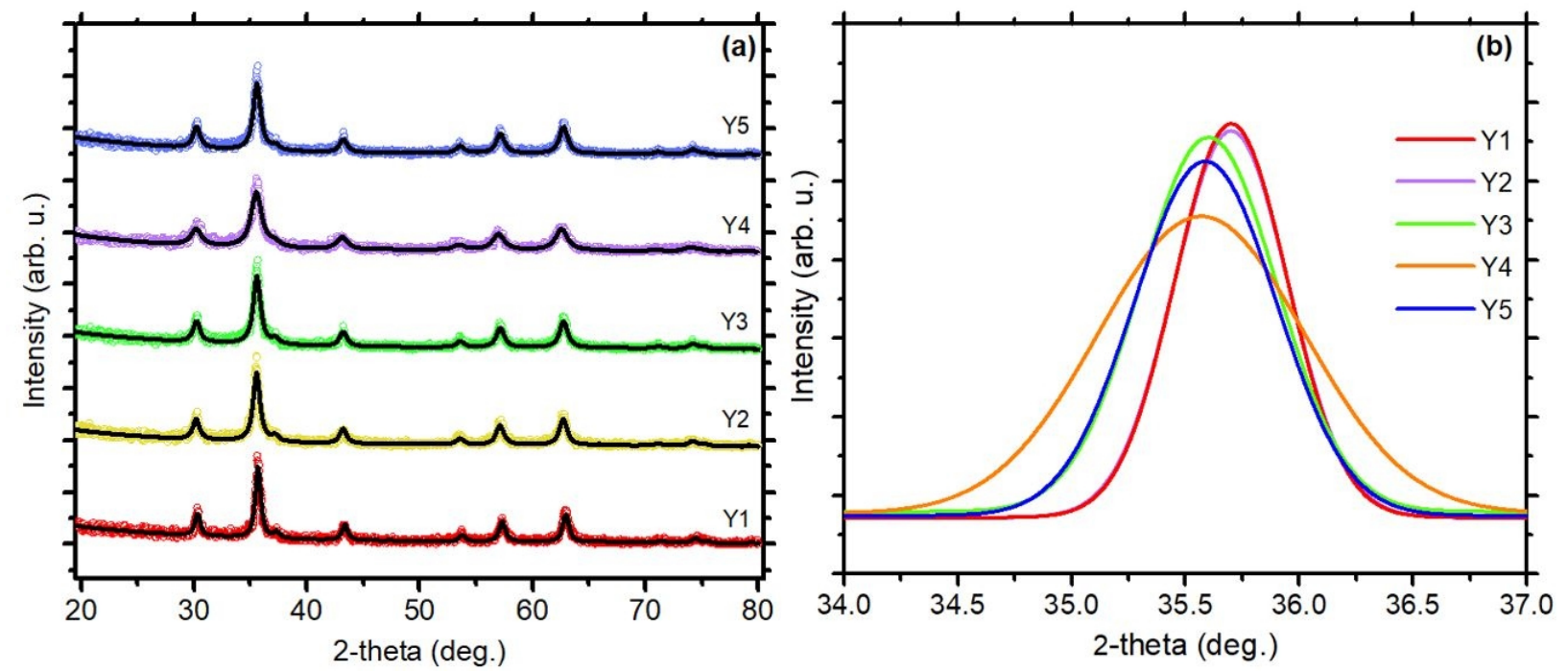

Figure 1. (a) XRD patterns and (b) highest diffraction peaks of the Zn-doped magnetite nanoparticles.

since the spinel structure was cubic with $V=a \times b \times c$, the crystal volume also increased with lattice parameters $a, b$, and $c$. The $\mathrm{Zn}^{2+}(74 \mathrm{pm})$ had a preference to replace place $\mathrm{Fe}^{2+}(61 \mathrm{pm})$ at the A-site. Meanwhile, $\mathrm{Fe}^{2+}(49 \mathrm{pm})$ partially transited to $\mathrm{Fe}^{3+}$ at B-site to neutralize the electricity of the crystal (Liu et al. 2012, 2016). The replacement of metallic ions with the larger ionic radius at A and B-sites expanded the lattice parameters and crystal volume for samples Y1-Y4. However, it was not observed for $Y_{5}$ with the highest $Z n$ content. The lattice parameters and crystal volume of $Y_{5}$ decreased compared to that of $\mathrm{Y}_{4}$. This phenomenon was believed because $\mathrm{Zn}^{2+}$ partially moved to the B-site. Furthermore, the crystallite size of the samples was in the range of 6.8(2)-8.6(3) nm.

FTIR experiment was conducted to study the sample functional groups further. The FTIR spectra in the wavenumber range of $400-4000 \mathrm{~cm}^{-1}$, as shown in Figure 2, provide information on the functional groups of the $\mathrm{Zn}$-doped magnetite nanoparticles. Based on the data analysis, the $\mathrm{Zn}$-doped magnetite nanoparticles indicated metal oxide (MO) groups originating from $\mathrm{Zn}-\mathrm{O}$ and $\mathrm{Fe}-\mathrm{O}$ functional groups in the wavenumber range of $400-700 \mathrm{~cm}^{-1}$ (Mozaffari et al. 2015). Specifically, the wavenumber range $480-410 \mathrm{~cm}^{-1}$ showed atomic vibrations from the metals $\left(\mathrm{Zn}^{2+}, \mathrm{Fe}^{2+}\right.$, and $\left.\mathrm{Fe}^{3+}\right)$ in tetrahedral and octahedral sites (Tehrani et al. 2012). These indicated that the spinel structure of the samples was successfully formed in agreement with the above XRD analysis. In the inverse spinel structure, the $\mathrm{Zn}-\mathrm{O}$ and $\mathrm{Fe}-\mathrm{O}$ functional groups at tetrahedral and octahedral sites, respectively, overlap and reduce the transmission intensity of the MOs. The present $\mathrm{Zn}$ ions with an atomic weight exceeding that of Fe ions led to a decrease in the transmission intensity of the metal bindings. Furthermore, the peaks at approximately 1630 and $3340 \mathrm{~cm}^{-1}$ originated from hydroxyl functional groups for the symmetrical and asymmetrical types, respectively (Mandal \& Natarajan 2015). Meanwhile, the weak peak at 2350 $\mathrm{cm}^{-1}$ can be attributed to $\mathrm{CO}_{2}$ molecules in the air (Gatelyte et al. 2011). 
Table I. XRD data analysis results of the Zn-doped magnetite nanoparticles.

\begin{tabular}{|c|c|c|c|c|c|c|c|c|}
\hline Samples & $2-\operatorname{theta}_{(311)}\left({ }^{\circ}\right)$ & $a=b=c(\AA)$ & $V(\AA)^{3}$ & Crystallite size $(\mathrm{nm})$ & $R w p$ & Gof & $M_{\mathrm{W}}(\mathrm{g} / \mathrm{mol})$ & Ionic distribution \\
\hline $\mathrm{Y}_{1}$ & 35.70 & $8.370(4)$ & $584.4(3)$ & $8.6(3)$ & 19.35 & 0.59 & 1852.4 & {$\left[\mathrm{Fe}_{1}^{3+}\right]_{\mathrm{A}}\left[\mathrm{Fe}_{1}^{2+} \mathrm{Fe}_{1}^{3+}\right]_{\mathrm{B}} \mathrm{O}_{4}^{2-}$} \\
$\mathrm{Y}_{2}$ & 35.69 & $8.383(3)$ & $589.1(3)$ & $8.2(2)$ & 19.56 & 0.61 & 1854.9 & {$\left[\mathrm{Zn}_{0.1}^{2+} \mathrm{Fe}_{0.9}^{3+}\right]_{\mathrm{A}}\left[\mathrm{Fe}_{0.9}^{2+} \mathrm{Fe}_{1.1}^{3+}\right]_{\mathrm{B}} \mathrm{O}_{4}^{2-}$} \\
$\mathrm{Y}_{3}$ & 35.60 & $8.389(4)$ & $590.4(4)$ & $7.9(2)$ & 19.14 & 0.60 & 1857.5 & {$\left[\mathrm{Zn}_{0.2}^{2+} \mathrm{Fe}_{0.8}^{3+}\right]_{\mathrm{A}}\left[\mathrm{Fe}_{0.8}^{2+} \mathrm{Fe}_{1.2}^{3+}\right]_{\mathrm{B}} \mathrm{O}_{4}^{2-}$} \\
$\mathrm{Y}_{4}$ & 35.56 & $8.394(5)$ & $591.4(7)$ & $7.4(1)$ & 19.79 & 0.62 & 1860.0 & {$\left[\mathrm{Zn}_{0.3}^{2+} \mathrm{Fe}_{0.7}^{3+}\right]_{\mathrm{A}}\left[\mathrm{Fe}_{0.7}^{2+} \mathrm{Fe}_{1.3}^{3+}\right]_{\mathrm{B}} \mathrm{O}_{4}^{2-}$} \\
$\mathrm{Y}_{5}$ & 35.58 & $8.391(5)$ & $590.8(6)$ & $6.8(2)$ & 19.39 & 0.62 & 1928.6 & {$\left[\mathrm{Zn}_{0.3}^{2+} \mathrm{Fe}_{0.7}^{3+}\right]_{\mathrm{A}}\left[\mathrm{Zn}_{0.1}^{2+} \mathrm{Fe}_{0.6}^{2+} \mathrm{Fe}_{1.3}^{3+}\right]_{\mathrm{B}} \mathrm{O}_{4}^{2-}$} \\
\hline
\end{tabular}




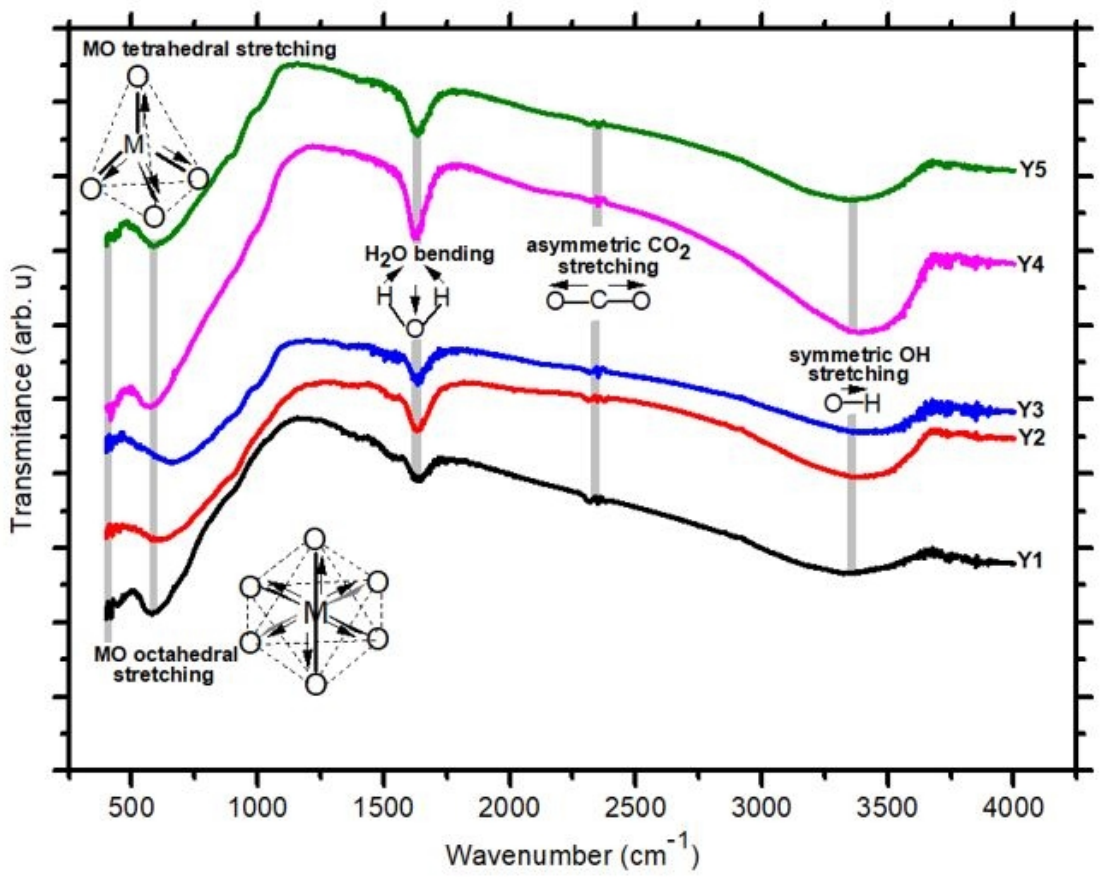

Figure 2. FTIR spectra of the Zn-doped magnetite nanoparticles.

The morphology and particle size distribution were further investigate based on the TEM results for the $Y_{1}, Y_{3}$, and $Y_{5}$ samples. Based on Figure 3a, it is found that the samples tend to form a spherical shape. The particle size distribution of the samples was analyzed using a log-normal distribution, and its results are presented in Figure $3 \mathrm{~b}$. Based on the analysis results, the average particle sizes were 13.7(7), 11.5(5), and 14.3(7) nm for $\mathrm{Y}_{1}, \mathrm{Y}_{3}$, and $\mathrm{Y}_{4}$, respectively. The particle size correlated with the nucleation mechanism and growth process during the synthesis process. In the early stage, the particle formation was constructed by cationic-anionic interaction to form monomers. In the next step, several monomers could grow fastly compare to other monomers depending on the balance-unbalance of population nuclei in the system. Theoretically, the particle growth linearly depends on the nucleation rate and density of nuclei (Kelton \& Greer 2010).

The particle size distribution of the samples varied from approximately 3 to $30 \mathrm{~nm}$ showing the polydispersity. The polydispersity index of $Y_{1}, Y_{3}$, and $Y_{5}$ were $0.33(4) 0.39(5)$, and $0.40(6)$, respectively. Based on the previous work, the polydispersity index value in the range of 0.08 to 0.70 indicated the mid-range polydispersity character (Asmawati et al. 2014). Although the TEM results showed evidence that the samples were successfully synthesized in nanometric size, the results could not be observed in the real particle size and distribution as well as the form and structure of the $\mathrm{Zn}$-doped magnetite ferrofluids because the TEM experiment was conducted for the dried Zn-doped magnetite ferrofluids. Therefore, a particular in-situ characterization was employed to investigate the real hierarchical structure as well as from and structure factors of the ferrofluids using the synchrotron SAXS technique.

The SAXS profiles, as shown in Figure $4 a$ are represented by intensity as a function of scattering vector $(q)$ as shown in Equation 3:

$$
I(q)=C \int_{0}^{\infty} P(q, R) S(q, R) R^{6} D(R) d R+B k g
$$



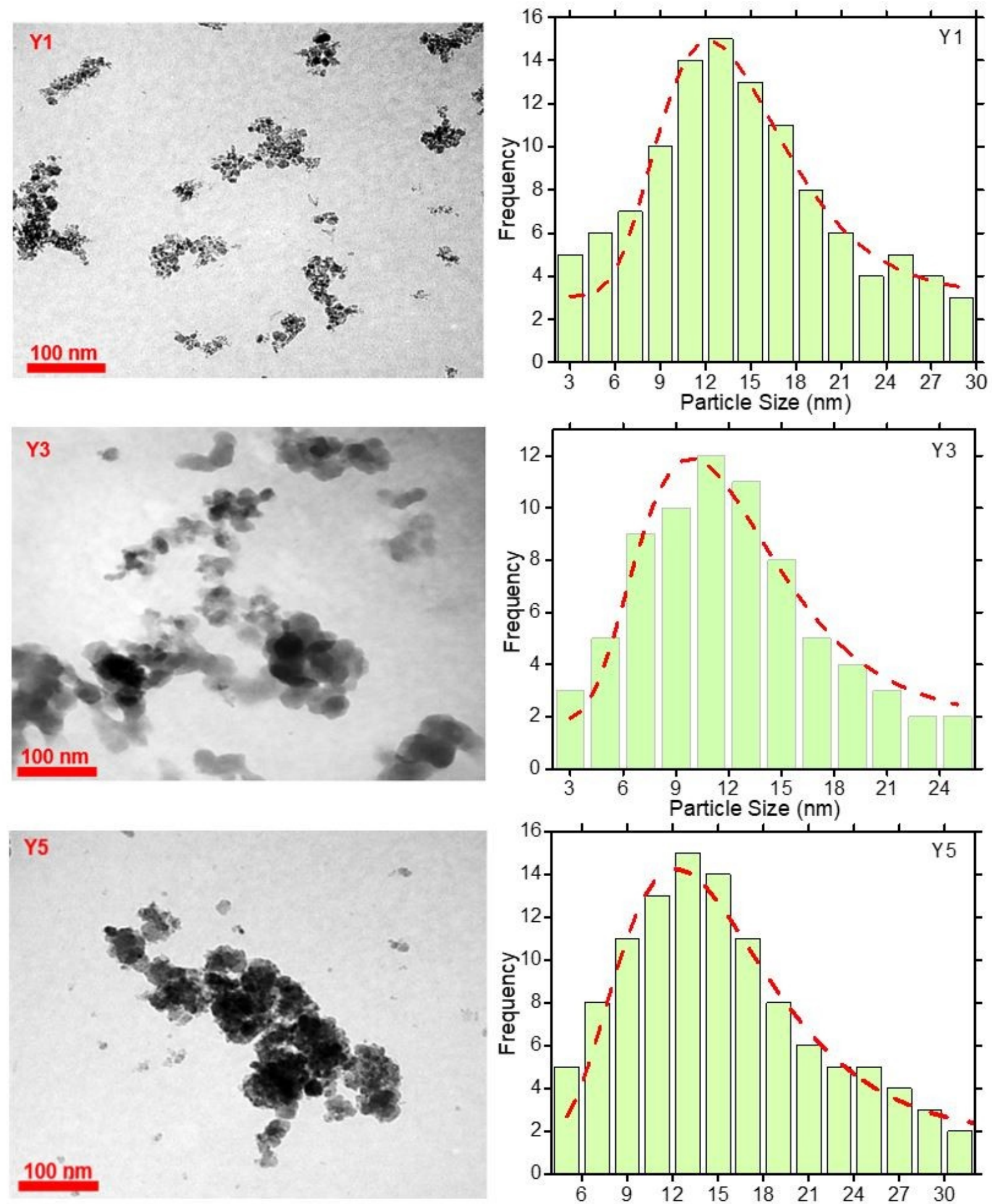

(a)

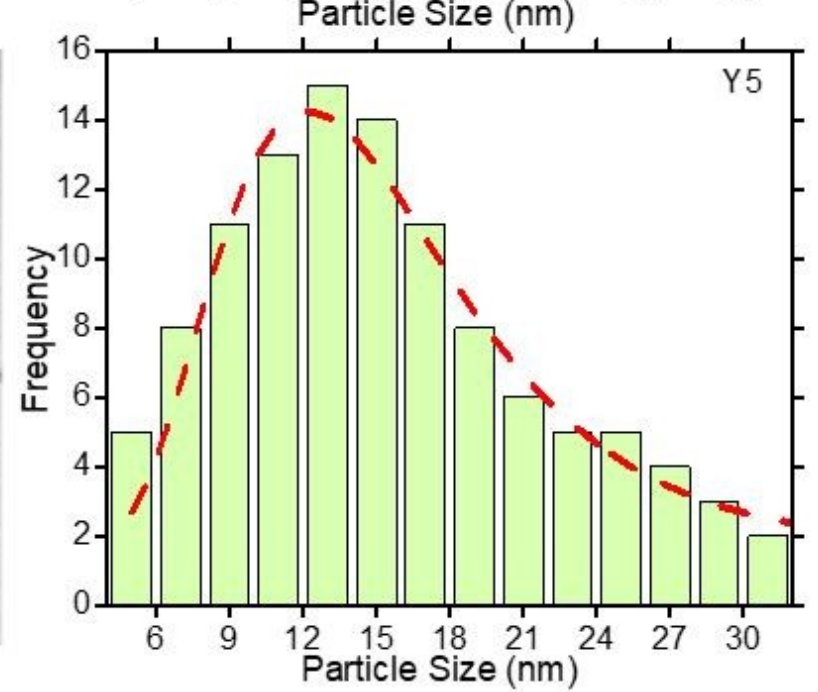

(b)

Figure 3. TEM images (a) and particle size distributions (b) of the dried Zn-doped magnetite ferrofluids. 


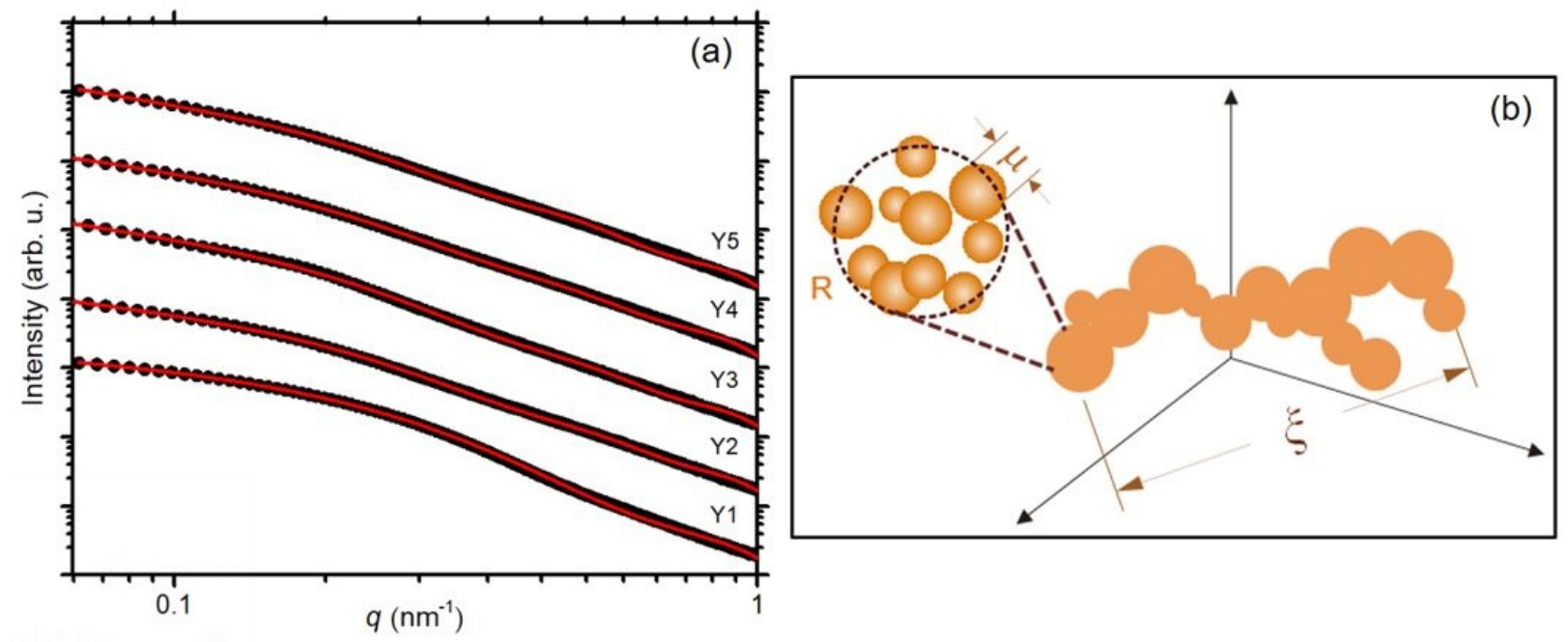

Figure 4. Synchrotron SAXS profiles of the Zn-doped magnetite ferrofluids (a); the black circles represent the experimental data, and solid red lines represent the fitting model. (b) Schematic of the three-dimensional structure of the $\mathrm{Zn}$-doped magnetite ferrofluids.

where $P(q, R)$ is the form factor, $S(q, R)$ is the structure factor, $D(R)$ is the particle size distribution, $C$ is the scale factor, $R$ is the particle size, and Bkg is the background. Furthermore, the SAXS data were analyzed employing a global fitting method using spherical form factor model, log-normal distribution, and mass fractal structure factor as presented in respective Equations $4-6$ (Yuliantika et al. 2020) as follows:

$$
\begin{gathered}
P(q, R)=9\left[\frac{\sin (q R)-q R \cos (q R)}{(q R)^{3}}\right]^{2} \\
L(R)=\frac{N}{\sigma R \sqrt{2 \pi}} \exp \left[\frac{\ln ^{2}\left(\frac{R}{R_{0}}\right)}{2 \sigma^{2}}\right] \\
S(q, R)=1+\frac{D}{R_{0}^{D}} \int_{0}^{\infty} R^{D-3} h(R, \xi) \frac{\sin q R}{q R} R^{2} d R
\end{gathered}
$$

where $L(R)$ represents the log-normal distribution function, $\varsigma$ represents the polydispersity index, $R_{0}$ represents the median radius of the particles, $N$ represents the normalization factor, $\xi$ represents the correlation length, and $D$ represents the fractal dimension (Taufiq et al. 2019). The fitting models are represented by solid red lines, and the SAXS data are represented by black circles, as shown in Figure 4a. Based on the figure, it is shown that the samples have two different slope characteristics in two $q$ regions. The low- $q$ region $0.06-0.20 \mathrm{~nm}^{-1}$ represents the fractal aggregate scattering from the structure factor, while the high-q region of $0.20-1.0 \mathrm{~nm}^{-1}$ represents monomer scattering from form factor. The SAXS data analysis results are presented in Table II.

The fitting results listed in Table II reveal that the primary particles $(\mu)$ of the $\mathrm{Zn}$-doped magnetite ferrofluids constructed the secondary particles $(R)$ in a fractal structure with a chain-like structure $(1.2<D<1.4)$ for samples $Y_{1}-Y_{4}$. However, the $Y_{5}$ sample has a more compact structure with $D=1.9$ 
Table II. Results of SAXS data analysis of the Zn-doped magnetic ferrofluids.

\begin{tabular}{|c|c|c|c|c|c|c|}
\hline \multirow{2}{*}{ Samples } & \multicolumn{2}{|c|}{ Monomer } & \multicolumn{4}{|c|}{ Mass fractal aggregates } \\
\cline { 2 - 7 } & $\mu(\mathrm{nm})$ & $\sigma$ & $R(\mathrm{~nm})$ & $\xi(\mathrm{nm})$ & $D$ & $N_{\text {agg }}$ \\
\hline$Y_{1}$ & 3.0 & 0.30 & 13.4 & 35.1 & 1.2 & 6 \\
$Y_{2}$ & 4.1 & 0.41 & 12.2 & 45.2 & 1.4 & 5 \\
$Y_{3}$ & 4.1 & 0.41 & 11.3 & 132.1 & 1.4 & 5 \\
$Y_{4}$ & 4.3 & 0.43 & 9.1 & 36.1 & 1.4 & 3 \\
$Y_{5}$ & 4.4 & 0.37 & 13.5 & 27.0 & 1.9 & 8 \\
\hline
\end{tabular}

with a shorter correlation length. The fractal structure with a chain-like structure was constructed by form factors of various sizes. The formation of fractal structure constructed by primary particles is visualized in Figure $4 \mathrm{~b}$. Based on the SAXS data analysis, it can be inferred that the Zn-doped magnetite ferrofluids build a hierarchical structure with the chain-like aggregation with the specific characteristics depending on the Zn composition.

A comprehensive structural characterization was conducted to reveal the structural properties of the samples. The XRD, TEM, FTIR, and SAXS results confirmed that high-quality Zn-doped magnetite nanoparticles were successfully synthesized by the sonochemical route using natural sand as a primary precursor. Furthermore, the proposed study can be used as a model system to fabricate a nanomaterial for biomedical applications. Therefore, to understand the effects of the Zn contents on the physical properties of the samples, basic physical properties, such as magnetic behaviors, were studied further, as shown in Figure 5.

The magnetic properties of the Zn-doped magnetite ferrofluids were investigated by VSM through magnetization curves, scanning the external magnetic field from -1 to $1 \mathrm{~T}$, as shown in Figure 5 . In this work, the ferrofluids as colloidal suspension contained the Zn-doped magnetite nanoparticles dispersed in a polar liquid. The magnetic particle concentration was maintained by approximately 14\%. The magnetic particles were stabilized using TMAH as a surfactant to create electrostatic repulsion on the surface. Theoretically, in the $\left[\mathrm{Fe}^{3+}\right]_{A}\left[\mathrm{Fe}^{2+} \mathrm{Fe}^{3+}\right]_{B} \mathrm{O}_{4}$ magnetite system, the magnetic moment is solely produced by $\mathrm{Fe}^{2+}$ ions at the octahedral site (B) because the exchange interaction between $\left[\mathrm{Fe}^{3+}\right]_{A}$ and $\left[\mathrm{Fe}^{3+}\right]_{B}$ is antiferromagnetic; therefore, they cancel each other, which is knows as super-exchange interaction. The $\mathrm{Zn}^{2+}$ ions entering the tetrahedral position (A) reduce the magnetization. The reduced magnetic moment at the tetrahedral site reduces the super-exchange interaction between $A$ and $B$ but increases it between $B$ and $B$. The stronger the interaction between $B$ and $B$, the lower the magnetic response (Cullity \& Graham 2008). In this work, the magnetization data were fitted using the Langevin equation, as written in Equation 7. Nevertheless, because the Zn-doped magnetite ferrofluids constructed a more complex structure, the aggregation should be taken into account to investigate the magnetization. Therefore, the magnetization data deviated from the Langevin theory originating from the presence of the aggregate in the ferrofluids. Theoretically, the Langevin theory can be applied to investigate the magnetization of the very dilute ferrofluids because 

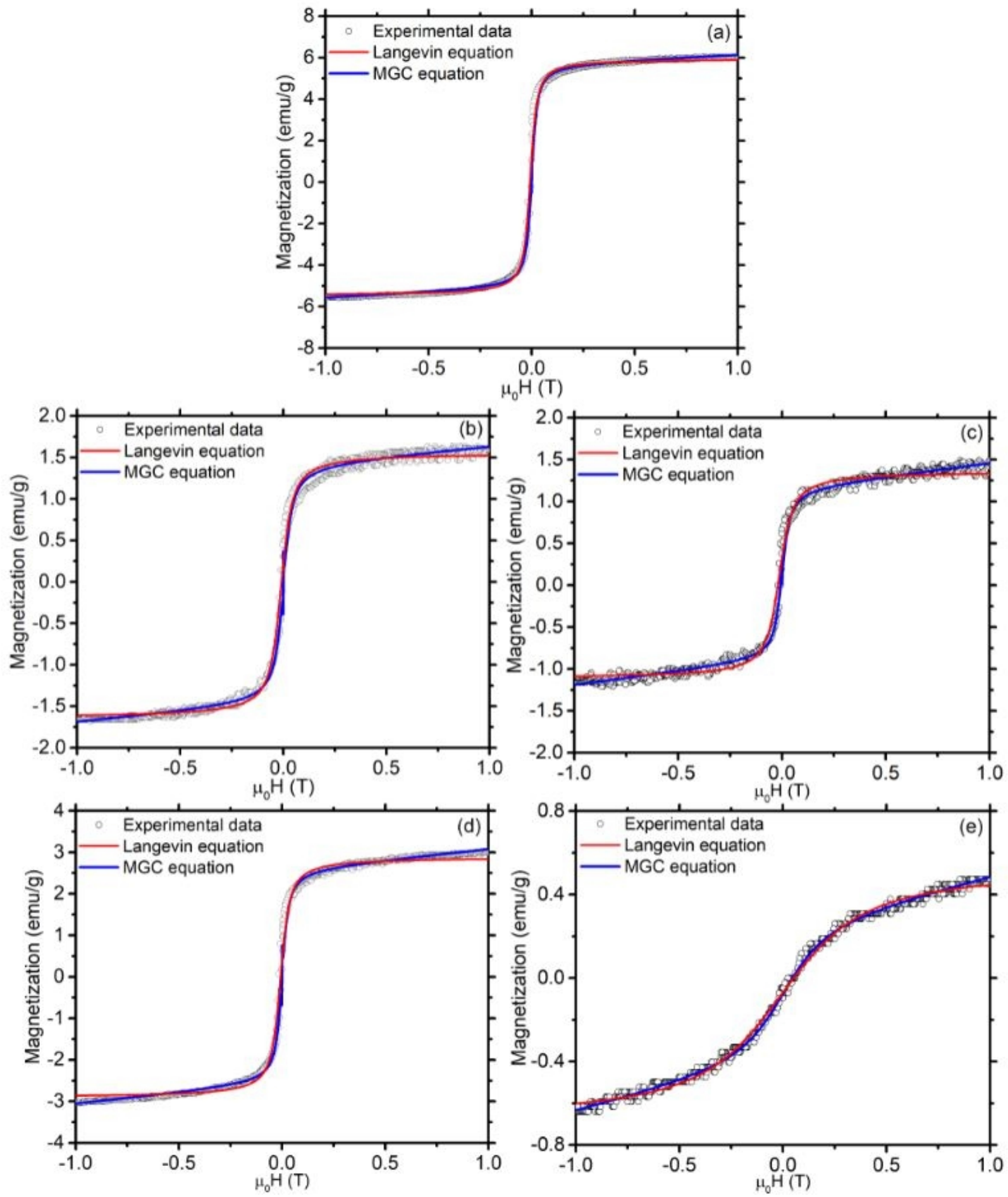

Figure 5. Magnetization curves of the samples (a) $Y_{1}$, (b) $Y_{2}$, (c) $Y_{3}$, (d) $Y_{4}$, and (e) $Y_{5}$. The solid red lines represent the Langevin equation, the solid blue lines represent the MGC equation, and the black circles represent the experimental data. 
of the magnetic particles exhibit as a monodisperse system without aggregation. However, in general cases, the ferrofluids construct aggregate with various shapes, as also shown in this work.

$$
M=M_{S}\left[\operatorname{coth}\left(\frac{\mu H}{k T}\right)-\frac{k T}{\mu H}\right]
$$

The $M$ and $M_{S}$ are the magnetization and saturation magnetization, $\mu$ is the magnetic moment, $H$ is the magnetic field, $k$ is the Boltzmann constant, and $T$ is the temperature.

The aggregation is created when the interaction energy between magnetic particles is stronger than that of thermal energy. As a consequence, the Zn-doped magnetite ferrofluids produce a fractal structure with a polydispersity system. The chain-like aggregation of the ferrofluids as a dissipative structure is constructed before applying an external magnetic field. It means that when the ferrofluids are applied by an external magnetic field, the aggregation consumes some magnetic field energy (Lin et al. 2010). Therefore, the magnetization of the $\mathrm{Zn}$-doped magnetite ferrofluids deviate from the Langevin theory. Furthermore, the average chain length of the ferrofluids does not significantly change when the external magnetic field increase, just arranges the chains to produce a better alignment along the direction of the external magnetic field (Wang et al. 2002).

Several simulation methods have been developed to study the magnetization characteristics of ferrofluids. A mean-field theory successfully describes the magnetization of the ferrofluids at a weak applied magnetic field. Nevertheless, the theory starts to overestimate the magnetization of the ferrofluids as the applied magnetic field increases. Therefore, a modified mean-field theory was also developed to study the magnetization of ferrofluids at the medium to high applied field (Kuznetsov 2018). However, it was only appropriate to study the ferrofluids in a monodisperse system. Therefore, in this work, we applied a model of gas-like compression (GMC) by considering the aggregation effect on the magnetization of the ferrofluids. The modification of Langevin function by the GMC combined with the susceptibility parameter is shown in Equations 8-10 (Li et al. 2007):

$$
\begin{gathered}
M=M_{r}+M_{S}\left[\operatorname{coth} \alpha-\frac{1+\ln \left(\frac{\varphi H}{\varphi}\right)}{\alpha}\right]+\chi_{H} \\
\varphi_{H}=(0.638-\varphi) \tanh \left(\gamma(\varphi \alpha)^{2}\right)+\varphi \\
\alpha=\frac{\mu_{0} \pi M_{S} d_{m}^{3} H}{6 k T}
\end{gathered}
$$

where $M_{r}, M_{S}, \chi, d_{m}, k$, and $T$ represent the remanent magnetization, saturation magnetization, susceptibility, magnetic particle size, Boltzmann constant, and temperature, respectively. Furthermore, $\varphi_{H}$ represents the aggregation volume fraction of the magnetic particles depends on the magnetic field, $\varphi$ represents the particle volume fraction, $\gamma$ represents the degrees of interaction between particles under the magnetic field, $d m$ represents magnetic particle size, and $\mu_{0}$ represents the permeability in a vacuum. Furthermore, the theoretical saturation magnetization of the $\mathrm{Zn}$-doped magnetite nanoparticles could be calculated using Equation 11 (Callister \& Rethwisch 2010). The $n_{B}$ is the magnetic moment per cell unit, $a$ is the unit cell edge length or lattice parameter that can be found in Table I, and $\mu_{B}$ is the magnitude of magneton Bohr. 


$$
M_{S}=\frac{n_{B} \mu_{B}}{a^{3}}
$$

Based on the data analysis results using Equations 8-10, the magnetic parameters are presented in Table III. Theoretically, the increasing Zn composition, the magnetic moment, and saturation magnetization of the $\mathrm{Zn}$-doped magnetite tend to increase from $\mathrm{Y}_{1}$ to $\mathrm{Y}_{4}$ and decrease for $\mathrm{Y}_{5}$. Such magnetic moment and saturation magnetization were calculated according to the ionic distribution of the $\mathrm{Zn}$-doped magnetite, as shown in Table I. However, the experimental data showed that the saturation magnetization of the $\mathrm{Zn}$-doped magnetite presented a different trend from the calculation. It means that the saturation magnetization of the samples was contributed not only by the $\mathrm{Zn}$ contribution but also by other parameters. Therefore, the form and structure factors, as well as the aggregation, should be taken into account to more deeply investigate the saturation magnetization of the samples.

Table III. Results of magnetization data analysis for the $\mathrm{Zn}$-doped magnetite ferrofluids.

\begin{tabular}{|c|c|c|c|c|c|c|c|}
\hline \multirow{2}{*}{ Samples } & \multirow{2}{*}{ Magnetic moment calc. $\left(\mu_{B}\right)$} & \multicolumn{3}{|c|}{ Saturation magnetization (emu/g) } & \multirow{2}{*}{$\left(\frac{\varphi_{H}}{H}\right)$} & \multirow{2}{*}{$\chi$} & \multirow{2}{*}{$\gamma$} \\
\hline & & Calc. & Langevin & MGC & & & \\
\hline$Y_{1}$ & 32.0 & 9.80 & 5.44 & 5.71 & 0.99 & 0.45 & 2 \\
\hline$Y_{2}$ & 36.8 & 11.06 & 1.45 & 1.59 & 0.98 & 0.22 & 6 \\
\hline$Y_{3}$ & 41.6 & 12.45 & 1.03 & 1.23 & 0.30 & 0.30 & 15 \\
\hline$Y_{4}$ & 46.4 & 13.89 & 2.60 & 2.89 & 0.97 & 0.49 & 1 \\
\hline$Y_{5}$ & 43.2 & 12.87 & 0.36 & 0.54 & 0.99 & 0.23 & 7 \\
\hline
\end{tabular}

When the magnetic moment per crystal unit of the $\mathrm{Zn}$-doped magnetite increases, the magnetic particle-particle interaction increases to form aggregation in the structure that is more compact. The Brownian motion keeps the magnetic particles in the carrier liquid dispersed randomly in the absence of an external magnetic field. This phenomenon is similar to gas molecules that spread in a container. However, the magnetic particles aggregate in the presence of an external magnetic field because of the magnetic particle-particle interaction. Therefore, the magnetic particles separate from the liquid matrix, producing a phase transition that is concentrated with magnetic particles, separates from a dilute phase, following the orientation of the particle magnetic moments along the direction of the magnetic field. In this case, the particle aggregation can be regarded as the particles being placed in an "aggregate space". Similar to compressed gas, the increasing magnetic field produces the more compact aggregate, decreasing the "aggregate space" (Li et al. 2007). The magnetic particles can be viewed in the "aggregate space", where the magnetic moment motion in the space was constrained by a matrix in the ferrofluids. Therefore, when the magnetization-demagnetization occurs, the magnetic moment is not easily oriented following an applied external magnetic field because it was trapped in the "aggregate space". In this case, the magnetic particles follow the behavior of gas-like compression (Han et al. 2009). Based on the fitting results, it was shown that the saturation magnetization of the $\mathrm{Zn}$-doped magnetite ferrofluids deviates from the Langevin theory. This phenomenon occurred because the $\mathrm{Zn}$-doped magnetite ferrofluids have an aggregation structure. When the ferrofluids 
aggregate with a shorter correlation length, the saturation magnetization would be optimum with the smooth curve because the single domain magnetic behavior is more dominant. However, when the ferrofluids have a longer correlation length, the saturation magnetization would deviate from the Langevin theory and produce an unstable curve. Therefore, the GMC plays a better model than the Langevin theory to fit the saturation magnetization of the $\mathrm{Zn}$-doped magnetite ferrofluids.
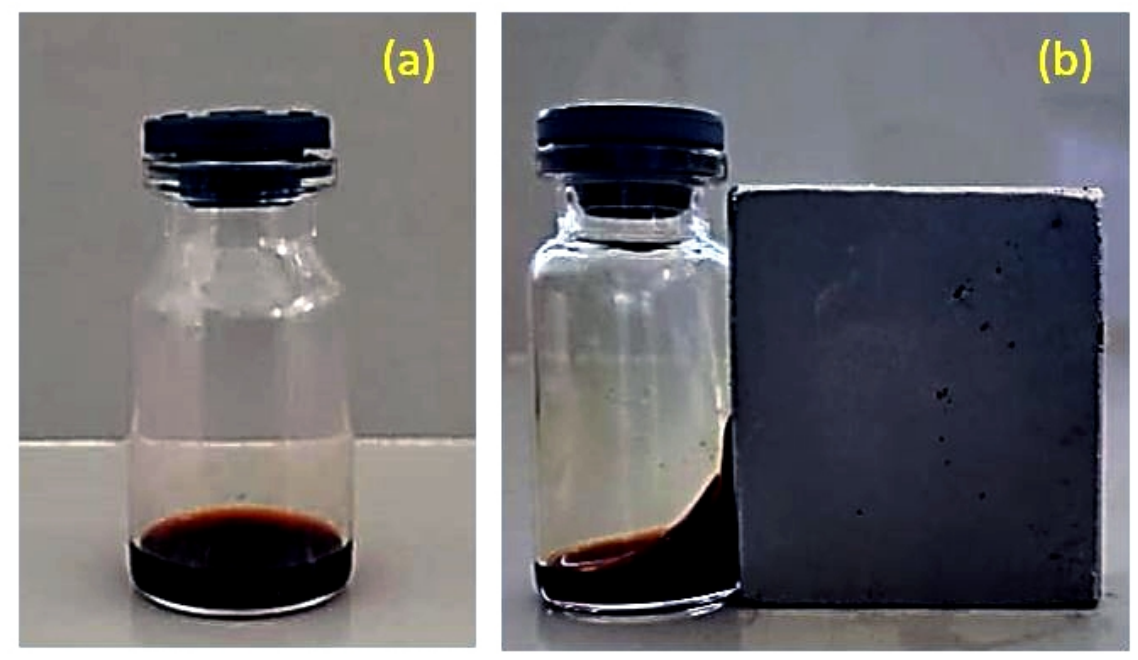

Figure 6. Photographs of the $\mathrm{Zn}$-doped aqueous magnetite ferrofluids (a) with and (b) without an external magnetic field.

The hierarchical structure of the Zn-doped magnetite ferrofluids obtained by SAXS data analysis is strongly related to the magnetic compression parameter $(\gamma)$. For $\gamma \cong 0$, the ferrofluids are not compressed to form aggregation. Therefore, Equation 8 becomes the Langevin equation that suitable to fit magnetization data for a monodisperse system (Li et al. 2007). However, for the higher $\gamma$ value, it represents the strong interaction particles or compact aggregation when the particles under an external magnetic field. Therefore, it affects the decreasing susceptibility, unstable magnetization curve, and decreasing saturation magnetization. The $\gamma$ parameter is appropriate to investigate the intrinsic magnetization of the $\mathrm{Zn}$-doped magnetite ferrofluids because this parameter is different from the magneto-dipole interaction following the thermodynamics crystal theory. In this work, the GMC with the $\gamma$ parameter was used to fit very well the magnetization curves, presenting that the model was in line with the experimental data. It means that the magnetization of the ferrofluids was contributed by the aggregation of the magnetic particles embedded in the matrix. Furthermore, the Zn-doped magnetite ferrofluids display superparamagnetic characteristics, with the remanence and coercive field being almost negligible. The prepared $\mathrm{Zn}$-doped ferrofluids are shown in Figure 6 . In the figure, the left side $6 a$ shows the ferrofluids without an external magnetic field while the right side $6 \mathrm{~b}$ shows the ferrofluids under an external magnetic field. Visually, the prepared Zn-doped magnetite ferrofluids display a good response to an external magnetic field.

Finally, the antibacterial activities were studied using a colony test with E. coli and B. subtilis bacteria. Based on Figure 7, generally, the Zn-doped magnetite ferrofluids show powerful antibacterial properties compared to the classical antibiotic, erythromycin, with gram-negative and positive bacteria. The bacterial killing activities of the $\mathrm{Zn}$-doped magnetite ferrofluids herein might be related to mechanical damage caused by their unique surface properties, wherein, according to the previous results, the magnetic nanoparticles could destroy the E. coli membrane due to the rough 


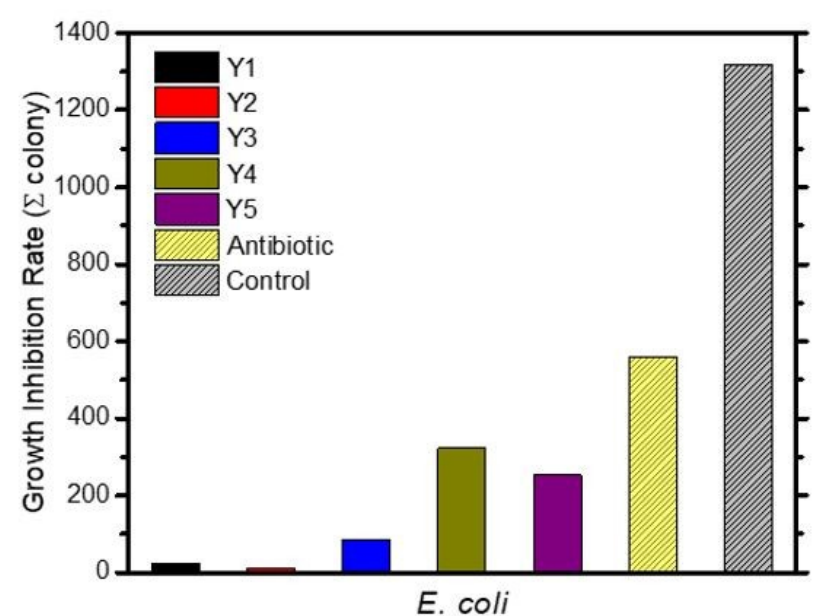

E. coli

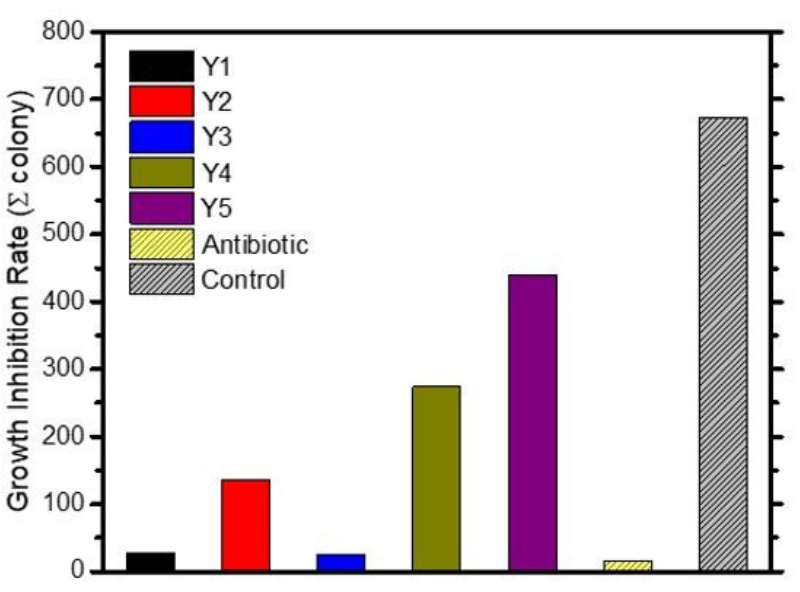

B. subtilis

Figure 7. Antibacterial activity of the $\mathrm{Zn}$-doped aqueous magnetite ferrofluids on $E$. coli (left-hand side) and $B$. subtilis (right-hand side) bacteria.

magnetic edges (Wang et al. 2007). Moreover, the membrane surface charge of the bacteria and nanoparticle surface charge suggest the influence of cell membrane disruption in the pathogen. It was hypothesized that Zn-doped magnetite nanoparticles interact with the bacterial membrane and change the zeta potential. Consequently, this interaction will affect van der Waals bonding and hydrophobic interactions on amines, carboxyl groups, and phosphates within the cell membrane to induce cell death (Xie et al. 2011). Interestingly, it was proposed that the essential role of Zn-doped magnetite ferrofluids are their bactericidal effect, which reduces bacterial growth but cannot induce complete cell death. It is only hypothesized that the treatment with magnetic nanoparticles produces reactive oxygen species, such as $\mathrm{H}_{2} \mathrm{O}_{2}, \mathrm{OH}$, and $\mathrm{O}^{2-}$ to increase bacterial death through oxidative stress, bacterial membrane peroxidation, and consequent DNA damage in both gram-negative and positive bacteria (Applerot et al. 2012, Stankic et al. 2016).

Excellent antibacterial activities were observed herein on E. coli growth rates. Treating bacteria with the magnetite ferrofluids doped with Zn significantly reduced their populations. Bacterial growth activity was decreased to a greater extent in gram-negative than that in gram-positive bacteria. One suggests that the colloidal stability achieved by combining Zn and magnetite can result in hydroxyl radical formation and exacerbate lipid and protein damage in the membrane to accelerate cell death. A previous finding showed that a mixture of $\mathrm{Zn}$ and ferrite enhanced antibacterial efficiency with E. coli with no toxic effects in mammalian cells (Ravichandran et al. 2015). The better performance of the magnetite ferrofluids doped with Zn also suggested an association with their ionic behavior. Physically, bacterial growth inhibition was correlated with anion-cation interactions of Zn-doped magnetite ferrofluids toward bacterial cells. Zn-doped magnetite ferrofluids were synthesized within a water-carrier medium to optimize the killing process. The presence of cations and $\mathrm{H}_{2} \mathrm{O}$ resulted in membrane shrinkage due to the binding activity of cations with bacterial membrane to induce plasmolysis and cell damage (Afkhami \& Renardy 2017). The improved cationic interaction and $\mathrm{H}_{2} \mathrm{O}$ accelerated peptide bond hydrolysis, in particular $50 \%$ of the peptidoglycan component of E. coli and approximately $35 \%$ of that of $B$. subtilis, occurred in gram-positive bacteria (Vollmer \& Seligman 
2010). We hypothesized that this caused differing viabilities of these bacteria. The primary role of Zn within Zn-doped magnetite ferrofluids may enhance cell death through binding to the functional groups of proteins and enzymes, decreasing the cell proliferation rate, disrupting the cell wall, inducing cytoplasmic damage, and thus causing bacterial cell apoptosis (Vedernikova 2015).

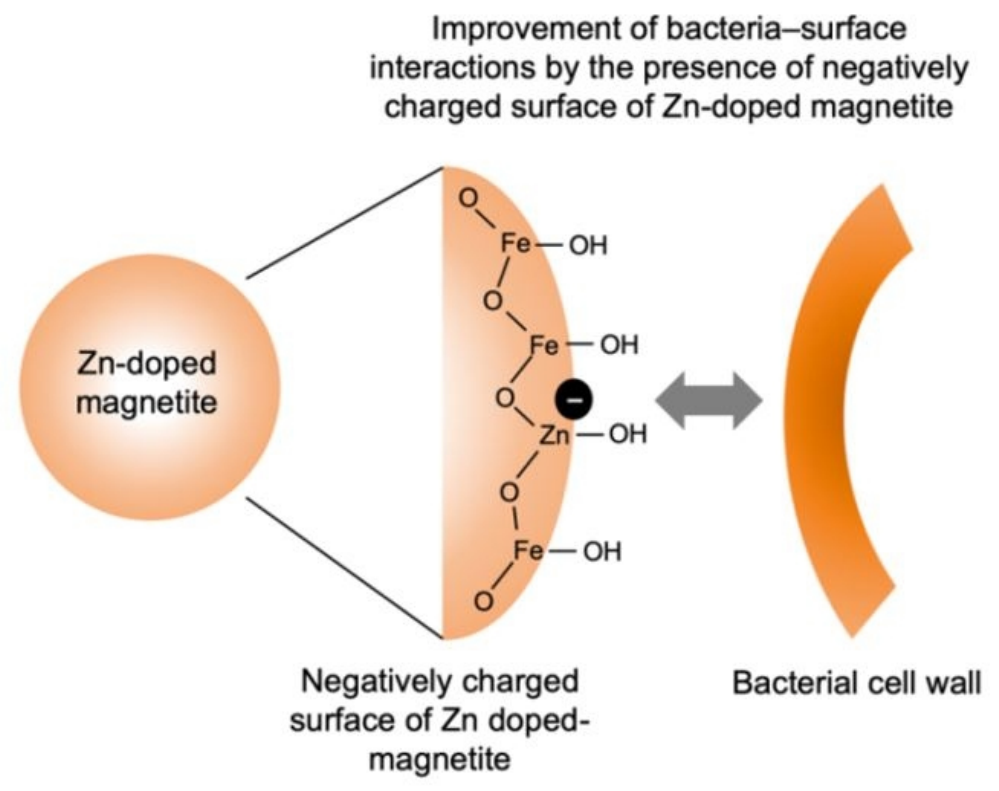

Figure 8. Improvement of antibacterial activity of the Zn-doped aqueous magnetite ferrofluids by the presence of the negatively charged surface.

The only credible, though complex, the relationship between the properties of $\mathrm{Zn}$-doped aqueous magnetite ferrofluids and their antibacterial activity was found when we considered the bacteria-surface interactions by the presence of negatively charged surface of Zn-doped magnetite. Prior studies have shown that $\mathrm{Zn}^{2+}$ was incorporated in the structure of magnetite to form the negatively charged surface of $\mathrm{Zn}$-doped magnetite as demonstrated by an increased lattice constant of the $\mathrm{Zn}$-doped magnetite nanoparticles originated from an increased $\mathrm{Zn}$ content. All of the results of the characterization obtained by FTIR, VSM, and synchrotron-based SAXS seems consistent with the possibility of the incorporation of $\mathrm{Zn}^{2+}$ in magnetite. A schematic illustration of the improvement of antibacterial activity of the $\mathrm{Zn}$-doped aqueous magnetite ferrofluids by the presence of a negatively charged surface is shown in Figure 8. In summary, two properties make Zn-doped magnetite an excellent antibacterial agent. The first property is the presence of the negatively charged surface. Secondly, the Zn-doped magnetite nanoparticles with the size are below $20 \mathrm{~nm}$. Therefore, Zn-doped magnetite ferrofluids prepared from natural sand are a new promising candidate material for use as an antibacterial agent for medical treatment in daily life applications.

\section{CONCLUSIONS}

High-quality Zn-doped magnetite ferrofluids have been successfully synthesized through a sonochemical route utilizing natural sand as the primary precursor. The Zn-doped magnetite nanoparticles crystallized in a spinel cubic structure. Generally, an increased lattice constant of the Zn-doped magnetite nanoparticles originated from an increased Zn content. The Zn-doped magnetite ferrofluids constructed secondary particles in aggregation with a fractal dimension $D<2$. The magnetic 
particles formed a chain-like structure with different correlation lengths. Under an external magnetic field, the magnetic particles in the ferrofluids placed aggregate space; therefore, the magnetization data would deviate from the Langevin equation. The magnetization mechanism of the Zn-doped magnetite ferrofluids was in line with the GMC with the susceptibility parameter. The aggregation structure played an essential role in the magnetization of the ferrofluids. Since the antibacterial activity of the $\mathrm{Zn}$-doped magnetite ferrofluids exhibited excellent performance as an antibacterial agent for $E$. coli and B. subtilis, one considers that the presence of the negatively charged surface and the nanoparticle size may contribute to the high antibacterial activity of Zn-doped magnetite ferrofluids. Therefore, the $\mathrm{Zn}$-doped magnetite ferrofluids can be used as a new alternative material for application in medical treatments.

\section{Acknowledgments}

This work was supported by the KEMENRISTEDIKTI Republic of Indonesia for AT (Grant number: 074/SP2H/LT/DRPM/2019).

\section{REFERENCES}

ADAMS SA, HAUSER JL, ALLEN AC, LINDQUIST KP, RAMIREZ AP, OLIVER S \& ZHANG JZ. 2018. $\mathrm{Fe}_{3} \mathrm{O}_{4} @ \mathrm{SiO}_{2}$ nanoparticles functionalized with gold and poly (vinylpyrrolidone) for bio-separation and sensing applications. ACS Appl Nano Mater 1(3): 1406-1412.

AFKHAMI S \& RENARDY Y. 2017. Ferrofluids and magnetically guided superparamagnetic particles in flows: a review of simulations and modeling. J Eng Math 107(1): 231-251.

AMARJARGAL A, TIJING LD, IM IT \& KIM CS. 2013. Simultaneous preparation of $\mathrm{Ag} / \mathrm{Fe}_{3} \mathrm{O}_{4}$ core-shell nanocomposites with enhanced magnetic moment and strong antibacterial and catalytic properties. Chem Eng Sci 226: 243-254.

ANJANA P, BINDHU M, UMADEVI M \& RAKHI R. 2018. Antimicrobial, electrochemical and photo catalytic activities of $\mathrm{Zn}$ doped $\mathrm{Fe}_{3} \mathrm{O}_{4}$ nanoparticles. J Mater Sci: Mater Electron 29(7): 6040-6050.

APPLEROT G, LELLOUCHE J, LIPOVSKY A, NITZAN Y, LUBART R, GEDANKEN A \& BANIN E. 2012. Understanding the antibacterial mechanism of $\mathrm{CuO}$ nanoparticles: revealing the route of induced oxidative stress. Small 8(21): 3326-3337.

ASMAWATI, MUSTAPHA WAW, YUSOP SM, MASKAT MY \& SHAMSUDDIN AF. 2014. Characteristics of cinnamaldehyde nanoemulsion prepared using APV-high pressure homogenizer and ultra turrax. In: AIP Conference Proceedings, American Institute of Physics, Vol. 1614, p. 244-250.
BEHDADFAR B, KERMANPUR A, SADEGHI-ALIABADI H, DEL PUERTO MORALES M \& MOZAFFARI M. 2012. Synthesis of aqueous ferrofluids of $\mathrm{Zn}_{x} \mathrm{Fe}_{3-x} \mathrm{O}_{4}$ nanoparticles by citric acid assisted hydrothermal-reduction route for magnetic hyperthermia applications. J Magn Magn Mater 324(14): 2211-2217.

CALLISTER WD \& RETHWISCH DG. 2010. Materials science and engineering: an introduction. J Wiley \& Sons, 812-813 $\mathrm{p}$.

CHEN WJ, TSAI PJ \& CHEN YC. 2008. Functional $\mathrm{Fe}_{3} \mathrm{O}_{4} / \mathrm{TiO}_{2}$ core/shell magnetic nanoparticles as photokilling agents for pathogenic bacteria. Small 4(4): 485-491.

CULLITY BD \& GRAHAM CD. 2008. Introduction to magnetic materials. the Institute of Electrical and Electronics Engineers, Inc, p. 178-189.

DAS B, MANDAL M, UPADHYAY A, CHATTOPADHYAY $P$ \& KARAK N. 2013. Bio-based hyperbranched polyurethane/ $/ \mathrm{Fe}_{3} \mathrm{O}_{4}$ nanocomposites: smart antibacterial biomaterials for biomedical devices and implants. Biomed Mater 8(3): 035003.

FARZIN L, SHEIBANI S, MOASSESI ME \& SHAMSIPUR M. 2019. An overview of nanoscale radionuclides and radiolabeled nanomaterials commonly used for nuclear molecular imaging and therapeutic functions. I Biomed Mater Res Part A 107(1): 251-285.

GATELYTĖ A, JASAITIS D, BEGANSKIENĖ A \& KAREIVA A. 2011. Sol-gel synthesis and characterization of selected transition metal nano-ferrites. Mater Sci 17(3): 302-307.

HAN S, LI J, GAO R, ZHANG T \& WEN B. 2009. Study of magnetisation behaviours for binary ionic ferrofluids. J Exp Nanosci 4(1): 9-19. 
JENCY DA, SATHYAVATHI K, UMADEVI M \& PARIMALADEVI R. 2020. Enhanced bioactivity of $\mathrm{Fe}_{3} \mathrm{O}_{4}-\mathrm{Au}$ nanocomposites-A comparative antibacterial study. Mater Lett 258: 126795

KELTON K \& GREER A. 2010. Precipitation in crystalline solids. In: Pergamon Materials Series, Elsevier, Vol. 15, p. 331-361.

KUCUK N. 2019. Thermoluminescence characteristics of terbium doped zinc borates. Crystals 9(11): 557.

KUZNETSOV AA. 2018. Equilibrium magnetization of a quasispherical cluster of single-domain particles. Phys Rev B 98(14): 144418.

LI J, HUANG Y, LIU X, LIN Y, BAI L \& LI Q. 2007. Effect of aggregates on the magnetization property of ferrofluids: A model of gaslike compression. Sci Technol Adv Mater 8(6): 448-454.

LIN YQ, LI J, LIU XD, ZHANG TZ, WEN BC, ZHANG QM \& MIAO H. 2010. Saturation magnetization and law of approach to saturation for self-formed ionic ferrofluids based on $\mathrm{MnFe}_{2} \mathrm{O}_{4}$ nanoparticles. Chin J Chem Phys 23(3): 325-330.

LIU J, BIN Y \& MATSUO M. 2012. Magnetic behavior of $\mathrm{Zn}$-doped $\mathrm{Fe}_{3} \mathrm{O}_{4}$ nanoparticles estimated in terms of crystal domain size. J Phys Chem C 116(1): 134-143.

LIU X, LIU J, ZHANG S, NAN Z \& SHI Q. 2016. Structural, magnetic, and thermodynamic evolutions of $Z n$-doped $\mathrm{Fe}_{3} \mathrm{O}_{4}$ nanoparticles synthesized using a one-step solvothermal method. J Phys Chem C 120(2): 1328-1341.

LV Z, WANG Q, BIN Y, HUANG L, ZHANG R, ZHANG $P$ \& MATSUO M. 2015. Magnetic behaviors of $\mathrm{Mg}$-and $\mathrm{Zn}$-doped $\mathrm{Fe}_{3} \mathrm{O}_{4}$ nanoparticles estimated in terms of crystal domain size, dielectric response, and application of $\mathrm{Fe} 3 \mathrm{O} 4 /$ carbon nanotube composites to anodes for lithium ion batteries. J Phys Chem C 119(46): 26128-26142.

MA S, ZHAN S, JIA Y \& ZHOU Q. 2015. Superior antibacterial activity of $\mathrm{Fe}_{3} \mathrm{O}_{4}-\mathrm{TiO}_{2}$ nanosheets under solar light. ACS Appl Mater Interfaces 7(39): 21875-21883.

MALEKI A, RAHIMI J \& VALADI K. 2019. Sulfonated $\mathrm{Fe}_{3} \mathrm{O}_{4} @ P V A$ superparamagnetic nanostructure: design, in-situ preparation, characterization and application in the synthesis of imidazoles as a highly efficient organic-inorganic Bronsted acid catalyst. Nano-Struct Nano-Objects 18: 100264.

MALEKI A, ZAND P, MOHSENI Z \& FIROUZI-HAJI R. 2018. Green composite nanostructure ( $\mathrm{Fe}_{3} \mathrm{O}$ @@PEG-SO${ }_{3} \mathrm{H}$ ): Preparation, characterization and catalytic performance in the efficient synthesis of $\beta$-amino carbonyl compounds at room temperature. Nano-Struct Nano-Objects 16: 31-37.
MANDAL S \& NATARAJAN S. 2015. Adsorption and catalytic degradation of organic dyes in water using $\mathrm{ZnO} / \mathrm{Zn}_{x} \mathrm{Fe}_{3-x} \mathrm{O}_{4}$ mixed oxides. J Environ Chem Eng 3(2): $1185-1193$.

MODARESI N, AFZALZADEH R, ASLIBEIKI B, KAMELI P, VARZANEH AG, ORUE I \& CHERNENKO V. 2019. Magnetic properties of $\mathrm{Zn}_{x} \mathrm{Fe}_{3-x} \mathrm{O}_{4}$ nanoparticles: A competition between the effects of size and $Z n$ doping level. J Magn Magn Mater 482: 206-218.

MOZAFFARI $M$, SHATOOTI S, JAFARZADEH M, NIYAIFAR M, AFTABI A, MOHAMMADPOUR H \& AMIRI S. 2015. Synthesis of $\mathrm{Zn}^{2+}$ substituted maghemite nanoparticles and investigation of their structural and magnetic properties. J Magn Magn Mater 382: 366-375.

PETRENKO V, ARTYKULNYI O, BULAVIN L, ALMÁSY L, GARAMUS $V$, IVANKOV O, GRIGORYEVA $N$, VEKAS L, KOPCANSKY P \& AVDEEV M. 2018. On the impact of surfactant type on the structure of aqueous ferrofluids. Colloids Surf A: Physicochem Eng Asp 541: 222-226.

RAJABI S \& SOHRABNEZHAD S. 2018. Fabrication and characteristic of $\mathrm{Fe}_{3} \mathrm{O}_{4} @ M O R @ C u O$ core-shell for investigation antibacterial properties. J Fluor Chem 206: $36-42$.

RAVICHANDRAN K, RATHI R, BANETO $M$, KARTHIKA K, RAJKUMAR P, SAKTHIVEL B \& DAMODARAN R. 2015. Effect of $\mathrm{Fe}^{+} \mathrm{F}$ doping on the antibacterial activity of $\mathrm{ZnO}$ powder. Ceram Int 41(3): 3390-3395.

SANCHETI SV \& GOGATE PR. 2017. A review of engineering aspects of intensification of chemical synthesis using ultrasound. Ultrason Sonochemistry 36: 527-543.

SEKHAR DC, DIWAKAR BS \& MADHAVI N. 2019. Synthesis, characterization and anti-bacterial screening of complex

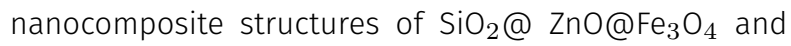
$\mathrm{SnO}_{2} @ \mathrm{ZnO} @ \mathrm{Fe}_{3} \mathrm{O}_{4}$. Nano-Struct Nano-Objects 19: 100374.

SIMMONS $M$, JONES N, EVANS D, WILES C, WATTS $P$, SALAMON S, CASTILLO ME, WENDE $H$, LUPASCU D \& FRANCESCONI M. 2015. Doping of inorganic materials in microreactors-preparation of $\mathrm{Zn}$ doped $\mathrm{Fe}_{3} \mathrm{O}_{4}$ nanoparticles. Lab Chip 15(15): 3154-3162.

SOOD A, ARORA V, SHAH J, KOTNALA R \& JAIN TK. 2017. Multifunctional gold coated iron oxide core-shell nanoparticles stabilized using thiolated sodium alginate for biomedical applications. Mater Sci Eng C 80: 274-281.

STANKIC S, SUMAN S, HAQUE F \& VIDIC J. 2016. Pure and multi metal oxide nanoparticles: synthesis, antibacterial and cytotoxic properties. J Nanobiotechnology 14(1): 1-20. 
TAUFIQ A ET AL. 2018. Preparation of superparamagnetic $\mathrm{Fe}_{3} \mathrm{O}_{4}$ nanoparticles from iron sand mediated by soft template and their performance as antibacterial agent. J Magn 23(3): 337-344.

TAUFIQ A, SUNARYONO S, HIDAYAT N, PUTRA E, OKAZAWA A, WATANABE I, KOJIMA N, PRATAPA S \& DARMINTO D. 2019. Nanostructure and Magnetic Field Ordering in Aqueous $\mathrm{Fe}_{3} \mathrm{O}_{4}$ Ferrofluids: A Small-Angle Neutron Scattering Study. At Indones 45(3): 165-172.

TEHRANI FS, DAADMEHR V, REZAKHANI A, AKBARNEJAD RH \& GHOLIPOUR S. 2012. Structural, magnetic, and optical properties of zinc-and copper-substituted nickel ferrite nanocrystals. J Supercond Nov Magn 25(7): 2443-2455.

VEDERNIKOVA I. 2015. Magnetic nanoparticles: Advantages of using, methods for preparation, characterization, application in pharmacy. Rev J Chem 5(3): 256-280.

VOLLMER W \& SELIGMAN SJ. 2010. Architecture of peptidoglycan: more data and more models. Trends Microbiol 18(2): 59-66.

WANG X, YANG F, YANG W \& YANG X. 2007. A study on the antibacterial activity of one-dimensional ZnO nanowire arrays: effects of the orientation and plane surface. Chem Commun 42: 4419-4421.

WANG Z, HOLM C \& MÜLLER HW. 2002. Molecular dynamics study on the equilibrium magnetization properties and structure of ferrofluids. Phys Rev E 66(2): 021405.

XIE Y, HE Y, IRWIN PL, JIN T \& SHI X. 2011. Antibacterial activity and mechanism of action of zinc oxide nanoparticles against Campylobacter jejuni. AEM 77(7): 2325-2331.

YAN L, ZHAO F, WANG J, ZU Y, GU Z \& ZHAO Y. 2019. A Safe-by-design strategy towards safer nanomaterials in nanomedicines. Adv Mater 31(45): 1805391.

YANG P, HU J, ZHOU XF, XIA J, SHI JJ \& HE J. 2017. Synthesis of graphene nanosheets modified with the $\mathrm{Fe}_{3} \mathrm{O}_{4} @$ @ phenol formaldehyde resin or PFR nanoparticles for their application in bio-imagine and thermal treatment. J Appl Polym Sci 134(26): 45007.

YEW YP, SHAMELI K, MIYAKE M, KHAIRUDIN NBBA, MOHAMAD SEB, NAIKI T \& LEE KX. 2020. Green biosynthesis of superparamagnetic magnetite $\mathrm{Fe}_{3} \mathrm{O}_{4}$ nanoparticles and biomedical applications in targeted anticancer drug delivery system: A review. Arab J Chem 13(1): 2287-2308.

YULIANTIKA D, TAUFIQ A \& PUTRA EGR. 2020. Hierarchical structure and antibacterial activity of olive oil based
$\mathrm{MZFe}_{2} \mathrm{O}_{4}$ ferrofluids. In: Journal of Physics: Conference Series, IOP Publishing, Vol. 1436, 012145 p.

ZHOU Z, LIU X, ZHANG M, JIAO J, ZHANG H, DU J, ZHANG B \& REN Z. 202O. Preparation of highly efficient ion-imprinted polymers with $\mathrm{Fe}_{3} \mathrm{O}_{4}$ nanoparticles as carrier for removal of $\mathrm{Cr}(\mathrm{VI})$ from aqueous solution. Sci Total Environ 699: 134334 . 


\section{How to cite}

TAUFIQ A, YULIANTIKA D, SUNARYONO S, SAPUTRO RE, HIDAYAT N, MUFTI N SUSANTO H, SOONTARANON S \& NUR H. 2021. Hierarchical Structure and Magnetic Behavior of Zn-Doped Magnetite Aqueous Ferrofluids Prepared from Natural Sand for Antibacterial Agents. An Acad Bras Cienc 93: e20200774. DOI 10.1590/0001-3765202120200774.

Manuscript received on May 22, 2020;

accepted for publication on December 7, 2020

\section{AHMAD TAUFIQ ${ }^{1}$}

https://orcid.org/0000-0002-0155-6495

\section{DEFI YULIANTIKA ${ }^{1}$}

https://orcid.org/0000-0002-3436-1651

\section{SUNARYONO SUNARYONO ${ }^{1}$}

https://orcid.org/0000-0001-5033-3549

\section{ROSY E. SAPUTRO 1}

https://orcid.org/0000-0001-6523-8181

\section{NURUL HIDAYAT ${ }^{1}$}

https://orcid.org/0000-0001-9232-7454

\section{NANDANG MUFTI ${ }^{1}$}

https://orcid.org/0000-0002-8260-8495

\section{HENDRA SUSANTO ${ }^{2}$}

https://orcid.org/0000-0002-3935-4848

\section{SIRIWAT SOONTARANON ${ }^{3}$}

https://orcid.org/0000-0001-9770-495X

\section{HADI NUR ${ }^{4}$}

https://orcid.org/0000-0002-4387-431X

${ }^{1}$ Universitas Negeri Malang, Faculty of Mathematics and Natural Sciences,Department of Physics, J. Semarang, No. 5, Malang 65145, Indonesia

${ }^{2}$ Universitas Negeri Malan, Faculty of Mathematics and Natural Sciences, Department of Biology, Jl. Semarang, No. 5, Malang 65145, Indonesia

35ynchrotron Light Research Institute, Nakhon Ratchasima, 111 University Avenue, Muang District, Nakhon Ratchasima 30000, Thailand

${ }^{4}$ Universiti Teknologi Malaysia, Ibnu Sina Institute for Scientific and Industrial Research, Centre for Sustainable Nanomaterials, 81310 Johor Bahru, Johor, Malaysia

Correspondence to: Ahmad Taufiq

E-mail: ahmad.taufiq.fmipa@um.ac.id

\section{Author contributions}

The manuscript was written through the contribution of all authors, specifically: conceptualization, A.T., H.N., N.M., and S.S.; methodology, A.T., H.S., N.M., and H.N.; investigation, D.Y., R.E.S, N.H., and H.S.; resources, D.Y., S.S. and N.H.; supervision, A.T. and H.N.; project administration, D.Y., N.H. and S.S.; funding acquisition, A.T. and D.Y. All authors have given their approval to the final version of the manuscript.

\section{(cc) BY}

